Supporting Information

\title{
Oppositely charged ions at water-air and water-oil interfaces: contrasting the molecular picture with thermodynamics
}

\author{
Odile Carrier $^{1 *}$, Ellen H.G. Backus ${ }^{2 *}$, Noushine Shahidzadeh ${ }^{1}$, Johannes Franz ${ }^{2}$, Manfred Wagner ${ }^{2}$, \\ Yuki Nagata ${ }^{2}$, Mischa Bonn ${ }^{2}$, Daniel Bonn ${ }^{1}$ \\ ${ }^{1}$ Van der Waals-Zeeman Institute, Institute of Physics, University of Amsterdam, Science Park 904, 1098 XH Amsterdam, \\ The Netherlands \\ ${ }^{2}$ Max Planck Institute for Polymer Research, Ackermannweg 10, 55128 Mainz, Germany \\ *O.C. and E.H.G.B. contributed equally
}

\section{$\underline{\text { Experimental details }}$}

Chemicals. Tetraphenylarsonium(V) chloride hydrate $\left(\mathrm{Ph}_{4} \mathrm{AsCl}\right)$ and sodium tetraphenylborate $\left(\mathrm{Ph}_{4} \mathrm{BNa}\right)$ were purchased from Sigma Aldrich and dissolved in Ultrapure Millipore ${ }^{\circledR}$ water for most experiments. To determine the precise molar mass NMR measurements were used to obtain the amount of water present in the crystal structure. Less than two water molecules were found per arsonium ion for the arsenide salt and none for the borate salt (see below).

Sum Frequency Generation (SFG) Vibrational Spectroscopy. SFG spectra were obtained by overlapping a visible and IR laser beam in space and time. Femtosecond seed pulses were provided by a mode-locked Ti:sapphire laser (Mai Tai SP, Spectra-Physics) and amplified in a regenerative amplifier (Spitfire Ace, Spectra-Physics) pumped by a Nd:YLF laser (Empower 45, Spectra-Physics) to generate a $4.8 \mathrm{~mJ}$ pulse at $800 \mathrm{~nm}$ with a pulse duration of $<40 \mathrm{fs}$ at a repetition rate of $1 \mathrm{kHz}$. Tunable IR pulses were generated by using one part of the laser output to pump an OPA system (TOPAS C, Light Conversion). The bandwidth of another part of the $800 \mathrm{~nm}$ beam was spectrally narrowed to $15 \mathrm{~cm}^{-1}$. The energy of the IR and VIS radiation was $\sim 4.8 \mu \mathrm{J}$ and $\sim 20 \mu \mathrm{J}$, respectively. Both beams were gently focused on the sample surface, i.e. the aqueous solutions in a homemade Teflon trough. The SFG signal was dispersed into a spectrograph (Acton SpectraPro 300i, Princeton Instruments) and detected by an EMCCD camera (Newton EM, Andor). All spectra were collected in ssp (s-SFG, s-VIS, p-IR) polarization combination, background subtracted and normalized with a non-resonant reference spectrum of a gold-coated $\mathrm{Si}$-wafer. The spectra were fit by assuming Lorentzian lineshapes (with amplitude $A_{n}$, frequency $\omega_{n}$, and full width half maximum (FWHM) linewidth $2 \Gamma_{n}$ for mode $n$ ) in combination with a frequency independent non-resonant signal (with amplitude $A_{\mathrm{NR}}$ and phase $\phi_{\mathrm{NR}}$ ):

$$
\chi^{(2)}\left(\omega_{I R}\right)=\chi_{N R}^{(2)}+\chi_{R}^{(2)}\left(\omega_{I R}\right)=A_{N R} e^{i \varphi_{N R}}+\sum_{n} \frac{A_{n}}{\omega_{I R}-\omega_{n}+i \Gamma_{n}} .
$$

The SFG intensity is subsequently given by: $I_{S F G}\left(\omega_{I R}\right) \propto\left|\chi^{(2)}\left(\omega_{I R}\right)\right|^{2} I_{V I S} I_{I R}$. In this study we used $\mathrm{n}=3$ : a $\mathrm{CH}$ vibration of the benzene ring and two water modes. The fit parameters are given in Table S1 and S2.

Phase resolved SFG. For the phase-resolved experiments the SFG signal from the sample interferes with a local oscillator generated from gold before the sample. Details for a similar experimental setup 
and data analysis can be found in Ref. ${ }^{1}$. The intensity of the IR and VIS radiation was for both roughly $6 \mu \mathrm{J}$ with incident angles of roughly 45 and $40^{\circ}$, respectively, onto the solutions in a stainless steel trough.

Nuclear Magnetic Resonance (NMR) Spectroscopy. To determine the amount of water present in the crystal structure of the two salts, NMR spectra were measured of well-defined concentrations of the salt solutions containing a known amount of dimethyl sulfone. $\mathrm{Ph}_{4} \mathrm{AsCl}$ or $\mathrm{Ph}_{4} \mathrm{BNa}$ were dissolved in dimethyl sulfoxide- $\mathrm{d}_{6}$. The spectra were recorded with a $5 \mathrm{~mm}$ PATXI ${ }^{1} \mathrm{H}_{-}{ }^{13} \mathrm{C} /{ }^{15} \mathrm{~N} / \mathrm{D}$ z-gradient on the 850 $\mathrm{MHz}$ spectrometer on a Bruker Avance III system. For a quantitative ${ }^{1} \mathrm{H}$ NMR measurements 32 transients were used with an $9,7 \mu \mathrm{s}$ long $90^{\circ}$ pulse and a $13600 \mathrm{~Hz}(16 \mathrm{ppm})$ spectral width together with a recycling delay of $40 \mathrm{~s}$. The $\mathrm{S} / \mathrm{N}$ (signal to noise) ratio was above 5000 for every used signal. The $\mathrm{T}_{1}$ relaxation time was measured with the inversion recovery method. ${ }^{2}$ As an internal reference standard dimethyl sulfone $\left(\left(\mathrm{CH}_{3}\right)_{2} \mathrm{SO}_{2}\right.$, Sigma Aldrich) was used and the weighted compounds were calculated against the standard via integrals of the proton signals (six protons from dimethyl sulfone and twenty protons from the four aromatic rings). ${ }^{3-4}$ The temperature was kept at $25^{\circ} \mathrm{C}$ and defined with a standard ${ }^{1} \mathrm{H}$ methanol NMR sample. The control of the temperature was realized with a VTU (variable temperature unit) and an accuracy of $+/-0.1 \mathrm{~K}$, which was checked with the standard Bruker Topspin 3.1 software.

Quantum chemistry calculation. The structures of $\mathrm{Ph}_{4} \mathrm{As}^{+}$and $\mathrm{Ph}_{4} \mathrm{~B}^{-}$ions were optimized at the BLYP/cc-pVDZ level of theory with the GAMESS software. ${ }^{5}$ The optimized structures had no molecular symmetry. Sequentially, by using the optimized structures, the electrostatic potential (ESP) fit charges were calculated. The group charges, core part (As/B with neighboring four carbon atoms) and benzene ring excluding the carbon atom attached to the As/B, were calculated by summing the ESP charges assigned to the atoms.

\section{Additional results}

\section{Raman spectra}

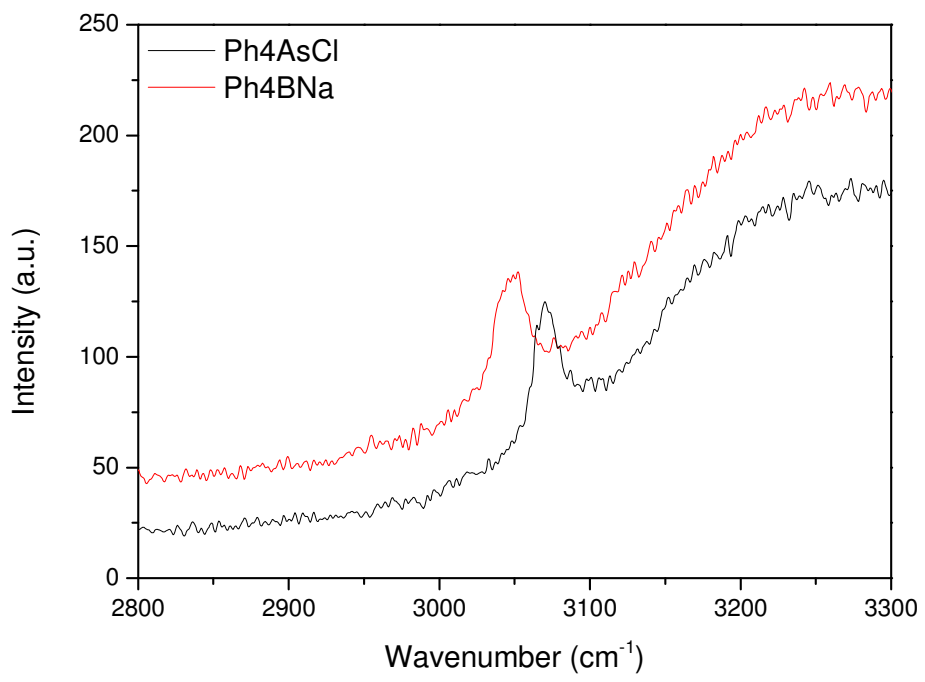

Figure S1. Raman spectra of $100 \mathrm{mM} \mathrm{Ph}_{4} \mathrm{AsCl}$ or $\mathrm{Ph}_{4} \mathrm{BNa}$, dissolved in water. 


\section{Phase resolved SFG spectra}

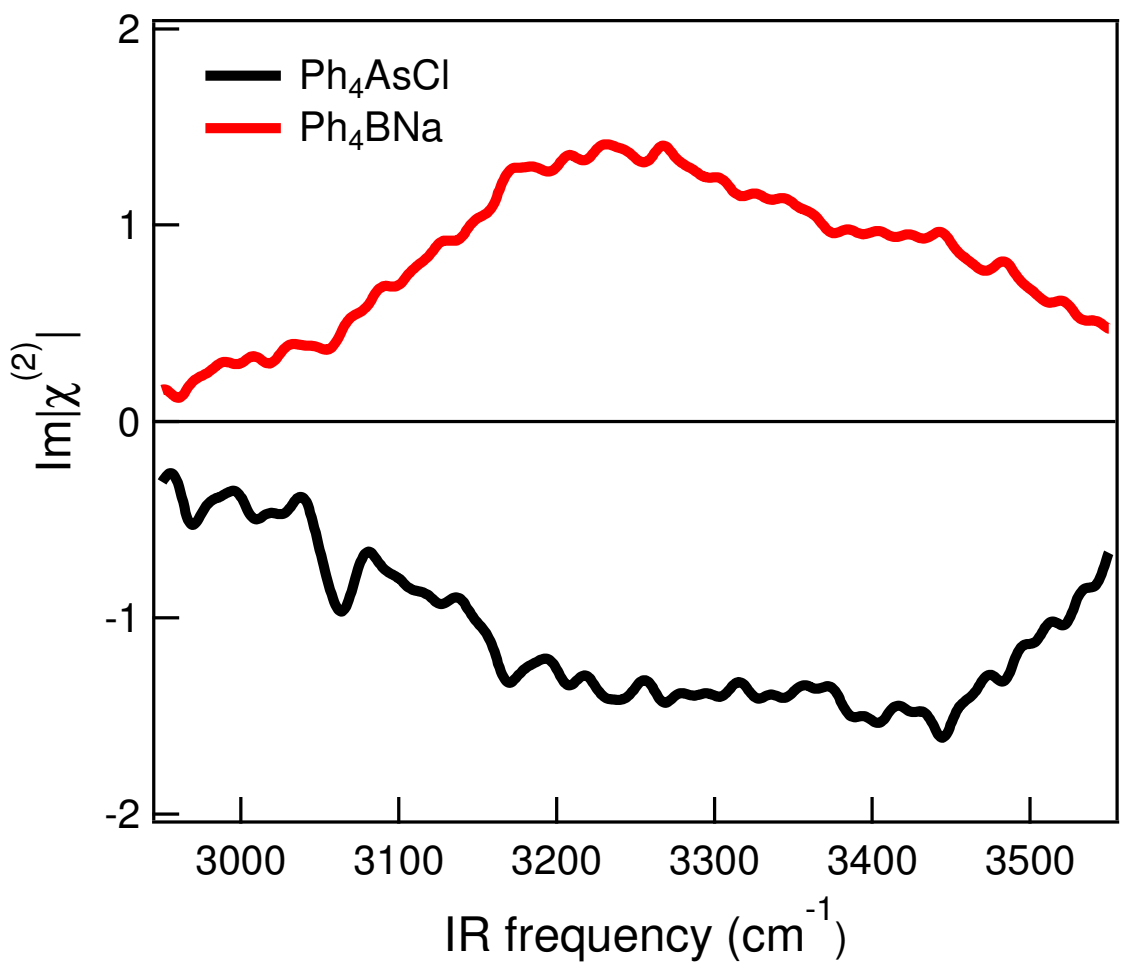

Figure S2. The imaginary part of the ssp SFG response for a $10 \mathrm{mM}$ solution of $\mathrm{Ph}_{4} \mathrm{AsCl}$ or $\mathrm{Ph}_{4} \mathrm{BNa}$, dissolved in water. Clearly, the water signal has opposite sign for both salts. A positive (negative) $\mathrm{OH}$ signal means water molecules pointing with their $\mathrm{H}$ atoms up (down). The $\mathrm{CH}$ signal around $3050 \mathrm{~cm}^{-1}$ has a negative response in both cases (very weak signal for $\mathrm{Ph}_{4} \mathrm{BNa}$ ).

\section{Sum Frequency Generation fit results}

Table S1. Fitting parameters for the concentration dependent SFG spectra at the air-water interface of the aqueous solution of $\mathrm{Ph}_{4} \mathrm{AsCl}$. A, $\omega$, and, $2 \Gamma$ are the amplitude, frequency and width (FWHM), respective$l y$, of the different Lorentzian modes. $A_{N R}$ and $\phi_{N R}=2.36$ radians are the nonresonant amplitude and phase, respectively.

\begin{tabular}{lllllllll}
\hline & $\mathrm{A}(1 \mathrm{mM})$ & $\mathrm{A}(2.5 \mathrm{mM})$ & $\mathrm{A}(5 \mathrm{mM})$ & $\mathrm{A}(10 \mathrm{mM})$ & $\mathrm{A}(25 \mathrm{mM})$ & $\mathrm{A}(50 \mathrm{mM})$ & $\omega\left(\mathrm{cm}^{-1}\right)$ & $2 \Gamma\left(\mathrm{cm}^{-1}\right)$ \\
\hline $\mathrm{CH}_{\text {arom }}$ & 0.25 & 0.40 & 0.56 & 0.84 & 1.45 & 1.59 & 3067 & 20.27 \\
$\mathrm{OH} \mathrm{I}$ & 39.91 & 52.16 & 54.68 & 57.07 & 57.58 & 55.53 & 3194 & 354.56 \\
$\mathrm{OH}$ II & 28.66 & 36.29 & 38.29 & 41.78 & 44.58 & 29.79 & 3484 & 320.43 \\
\hline $\mathrm{A}_{\mathrm{NR}}$ & 0.085 & 0.110 & 0.113 & 0.122 & 0.125 & 0.093 & & \\
\hline
\end{tabular}


Table S2. Fitting parameters for the concentration dependent SFG spectra at the air-water interface of the aqueous solution of $\mathrm{Ph}_{4} B N a$. A, $\omega$, and, $2 \Gamma$ are the amplitude, frequency and width (FWHM), respective$l y$, of the different Lorentzian modes. $A_{N R}$ and $\phi_{N R}=2.36$ radians are the nonresonant amplitude and phase, respectively.

\begin{tabular}{lllllllll}
\hline & $\mathrm{A}(1 \mathrm{mM})$ & $\mathrm{A}(2.5 \mathrm{mM})$ & $\mathrm{A}(5 \mathrm{mM})$ & $\mathrm{A}(10 \mathrm{mM})$ & $\mathrm{A}(25 \mathrm{mM})$ & $\mathrm{A}(50 \mathrm{mM})$ & $\omega\left(\mathrm{cm}^{-1}\right)$ & $2 \Gamma\left(\mathrm{cm}^{-1}\right)$ \\
\hline $\mathrm{CH}_{\text {arom }}$ & 0.18 & 0.21 & 0.20 & 0.37 & 0.49 & 0.90 & 3046 & 20.27 \\
$\mathrm{OH} \mathrm{I}$ & -33.88 & -35.93 & -34.52 & -44.91 & -39.85 & -51.23 & 3194 & 354.56 \\
$\mathrm{OH}$ II & 5.86 & -0.61 & 0.95 & -7.80 & -13.60 & -6.59 & 3484 & 320.43 \\
\hline $\mathrm{A}_{\mathrm{NR}}$ & 0.030 & 0.040 & 0.026 & 0.034 & 0.028 & 0.008 & &
\end{tabular}

\section{NMR spectra in DMSO to determine amount of water}

From the relative intensity of the signal at $3 \mathrm{ppm}$ originating from the protons from dimethyl sulfone and the protons from the phenyl rings between 6.8 and $8 \mathrm{ppm}$ the amount of crystal water in the salts could be quantitative determined. For this experiment the dimethyl sulfone and the two salts were weighted with very high precision.

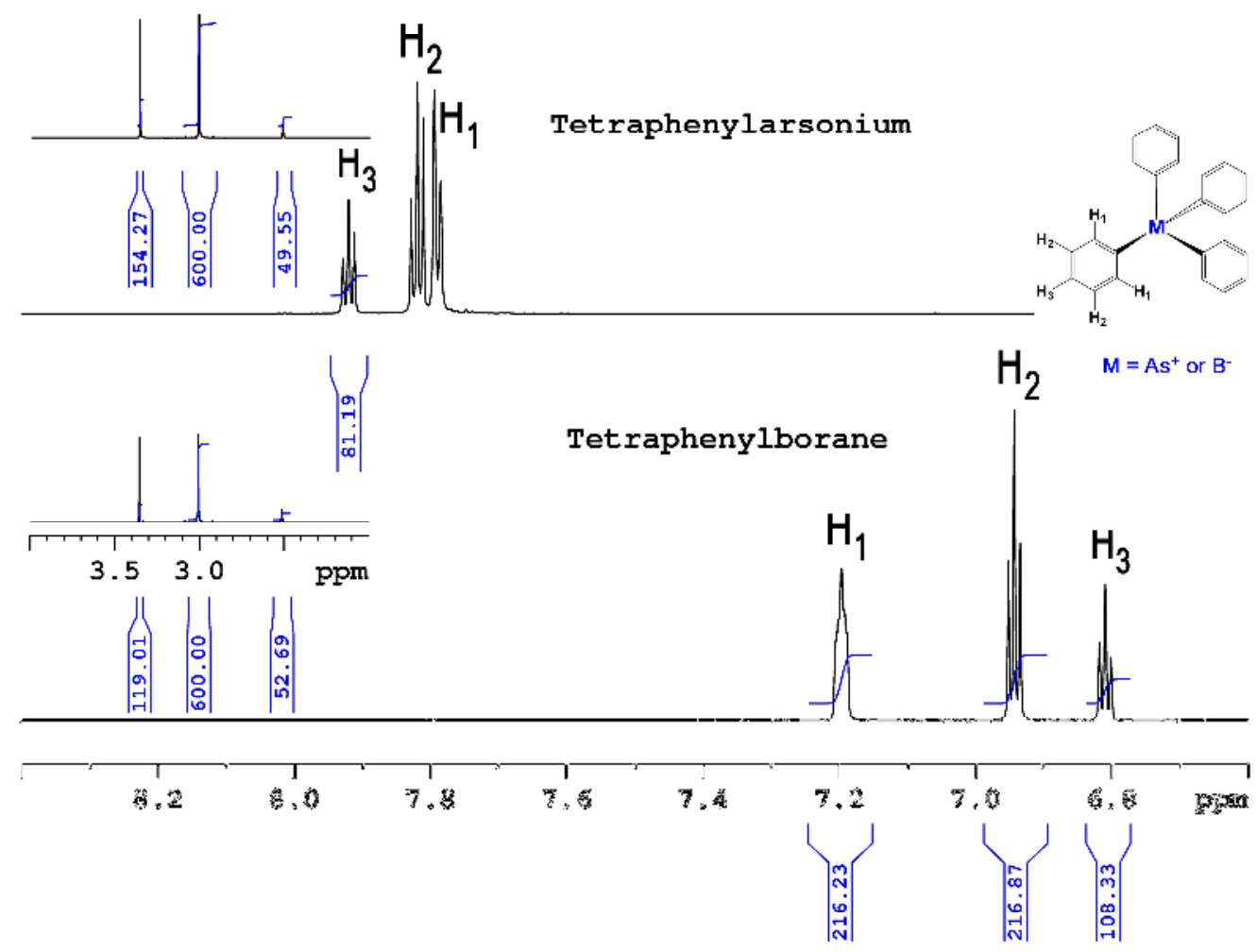

Figure S3. Quantitative ${ }^{l} \mathrm{H} N M R$ spectra of $(A) \mathrm{Ph}_{4} \mathrm{AsCl}$ and (B) $\mathrm{Ph}{ }_{4} B N a$. All spectra were acquired in presence of a knowm amount of dimethyl sulfone. The signal (see inset) at 2.5, 3, and 3.35 ppm originate from DMSO-d $d_{6}$, dimethyl sulfone, and water, respectively. The signals from the benzene protons are assigned in the figure. 


\section{$\underline{\text { References }}$}

(1) Ohto, T.; Backus, E. H. G.; Hsieh, C.-S.; Sulpizi, M.; Bonn, M.; Nagata, Y., Lipid Carbonyl Groups Terminate the Hydrogen Bond Network of Membrane-Bound Water. J. Phys. Chem. Lett. 2015, 6, 4499-4503.

(2) L.Vold, R.; Waugh, J. S.; Klein, M. P.; Phelps, D. E., Measurement of Spin Relaxation in Complex Systems J. Chem. Phys. 1968, 48 3831-3832.

(3) Malz, F. Validierung Der ${ }^{1}$ H-NMR-Spektroskopie Als Primäre Analytische Methode. Bundesanstalt für Materialforschung und -prüfung 1999.

(4) Malz, F. Quantitative NMR-Spektroskopie Als Referenzverfahren in Der Analytischen Chemie. Humboldt-Universität Berlin, 2003.

(5) Schmidt, M. W., et al., General Atomic and Molecular Electronic Structure System. J. Comput. Chem. 1993, 14, 1347-1363. 